\title{
VARIABILIDADE ESPACIAL DE ALGUNS ATRIBUTOS QUÍMICOS EM ÁREAS CULTIVADAS COM SOJA E ARROZ NO ESTADO DE RORAIMA - CONTRIBUIÇÕES DA AGRICULTURA DE PRECISÃO
}

\author{
Shirlene Souza Oliveira ${ }^{1}$; Deymeson Mateus Soares da Silva ${ }^{1}$; Rian Antonio dos Reis \\ Ribeiro ${ }^{1}$; Jairo dos Santos Reis ${ }^{1}$; Jorge Luís Padilha Costa ${ }^{1}$; Eduardo Cézar Medeiros \\ Saldanha ${ }^{3}$. \\ ${ }^{1}$ Universidade Federal Rural da Amazônia. Capitão Poço, Pará, Brasil. oliveira.shirlene2010@ gmail.com \\ ${ }^{2}$ Universidade Federal Rural da Amazônia. Capitão Poço, Pará, Brasil. eduardo.saldanha@ufra.edu.br
}

\begin{abstract}
RESUMO: O Estado de Roraima possui uma superfície de $225.116 \mathrm{~km}^{2}$, representando $2,64 \%$ do território nacional e 5,81\% da Região Norte. O conhecimento detalhado da variabilidade espacial dos atributos da fertilidade do solo pode aperfeiçoar as aplicações localizadas de corretivos e fertilizantes. Objetivou-se neste trabalho, avaliar a variabilidade de alguns atributos $\left(\mathrm{pH}, \mathrm{Ca}^{+2}\right.$ e $\left.\mathrm{P}\right)$ químicos de solos sob cultivo de soja e arroz no estado de Roraima, com auxílio da Agricultura de Precisão. A amostragem do solo foi realizada em 3265 ha, com grade amostral de 5 ha, perfazendo o total de 653 pontos amostrais (amostras compostas). Cada amostra composta foi georreferenciada e formada a partir de 10 amostras simples coletadas em um círculo ao redor de cada grade de amostragem, resultando assim num total de 6530 amostras simples coletadas. Para os solos avaliados com agricultura de precisão dos dois municípios, os atributos mostraram variação de níveis satisfatórios (P disponível) a deficientes (Ca disponível), e muito baixo ( $\mathrm{pH})$.
\end{abstract}

PALAVRAS-CHAVE: fertilidade do solo, georreferenciamento, grãos.

\section{SPATIAL VARIABILITY OF SOME CHEMICAL ATTRIBUTES IN AREAS WITH SOY AND RICE CULTIVATED IN THE STATE OF RORAIMA - CONTRIBUTIONS OF PRECISION FARMING}

\begin{abstract}
The state of Roraima has an area of $225116 \mathrm{~km} 2$, representing $2.64 \%$ of the national territory and $5.81 \%$ in the northern region. detailed knowledge of the spatial variability of soil fertility attributes can improve the localized applications of lime and fertilizers. The objective of this study was to evaluate the variability of some attributes (ph, ca +2 and p) chemical soil under cultivation of soybean and rice in the state of Roraima, with the help of precision agriculture. Soil sampling was conducted in 3265 ha, with sampling grid of 5 ha, totaling 653 sampling points (composite samples). Each composite sample was georeferenced and formed from 10 single samples collected in a circle around each sampling grid, thus resulting in a total of 6530 samples collected simple. For soils assessed with precision agriculture of the two municipalities, the attributes showed satisfactory levels of variation (available $\mathrm{p}$ ) disabled (ca available), and very low $(\mathrm{pH})$.
\end{abstract}

KEYWORDS: georeferencing, grains, soil fertility. 
O Estado de Roraima possui uma superfície de $225.116 \mathrm{~km}^{2}$, representando $2,64 \%$ do território nacional e 5,81\% da Região Norte (MELO et al., 2003). O Estado de Roraima aparece na relação dos produtores de grãos como uma área de fronteira agrícola onde a soja começou a ser plantada recentemente. Em 2008 foram plantados 6.500 ha, com produtividade média estimada de $2.940 \quad \mathrm{~kg} \mathrm{ha}^{1}$ (GIANLUPPI et al., 2009).

No Brasil a produção de soja na safra 2011/2012 foi de 66,37 milhões de toneladas, e Roraima teve uma produção de 10,4 milhões de toneladas (CONAB, 2012). O cultivo de arroz em Roraima teve início na colonização do antigo território de Roraima em 1944. No entanto, a exploração da cultura em escala comercial foi efetivada a partir de 1977. Na safra 2007/2008 o arroz continuava sendo a cultura de maior importância econômica do estado de Roraima, ocupando uma área de 22.200 ha, com produção de 125.880 toneladas de arroz em casca e produtividade média de arroz de sequeiro e irrigado de $5.670 \mathrm{~kg} \mathrm{ha}^{-1}$, considerada a mais alta do Brasil (SAKAZAKI et al., 2008).

A fertilidade do solo pode ser modificada pela ação antrópica com certa facilidade para se adequar às exigências das plantas cultivadas. Mesmo em condições naturais, o fluxo de nutrientes no sistema solo-planta-atmosfera é dinâmico e, portanto, passível de mudanças, cujas magnitudes dependem das condições ecológicas locais e da interação com a exploração agrícola (COSTA et al., 2008).

A partir do impulso das técnicas de agricultura de precisão, o estudo da variabilidade espacial da disponibilidade de nutrientes minerais em solos agrícolas tornou-se uma ferramenta eficiente para a introdução de novas práticas de adubação. O conhecimento detalhado da variabilidade espacial dos atributos da fertilidade do solo e da produtividade pode aperfeiçoar as aplicações localizadas de corretivos e fertilizantes, melhorando dessa maneira o controle do sistema de produção das culturas, reduzindo os custos gerados pela alta aplicação de insumos e a degradação ambiental provocada pelo excesso de nutrientes (VARASCHINI, 2012).

Desta forma, objetivou-se neste trabalho, avaliar a variabilidade de alguns atributos químicos de solos sob cultivo de soja e arroz no estado de Roraima, com auxílio da Agricultura de Precisão.

O estudo foi realizado em cinco diferentes propriedades agrícolas com plantio de grãos de soja e arroz no Estado de Roraima, nos municípios de Boa Vista e Bonfim, com equidistância de $125 \mathrm{~km}$ entre si, na zona climática tropical, nas coordenadas geográficas entre os meridianos $60^{\circ}$ e $17^{\prime}$ e $61^{\circ}$ e paralelos 
$2^{\circ} 18^{\prime}$ e $3^{\circ} 37^{\prime}$. Entre os principais tipos de solos presentes no Estado, estão os Latossolos Amarelos (MELO et al., 2003).

O Estado apresenta três tipos climáticos, todos com altas temperaturas, associados aos tipos característicos de vegetação, cujas médias mensais apresentam uma amplitude anual que não ultrapassa a $5^{\circ} \mathrm{C}$ (MELO et al., 2003).

As informações utilizadas foram obtidas de um banco de dados provenientes de amostras de solos coletadas, na profundidade de $0-20 \mathrm{~cm}$, no ano de 2009.

A amostragem do solo foi realizada em uma área total de aproximadamente 3265 ha, com grade amostral de 5 ha, perfazendo o total de 653 pontos amostrais (amostras compostas). Cada amostra composta foi georreferenciada e formada a partir de 10 amostras simples coletadas em um círculo ao redor de cada grade de amostragem, resultando assim num total de 6530 amostras simples coletadas.

As coletas de solo foram realizadas com auxílio de um trado de rosca de aço inoxidável automatizado com motor elétrico, instalado em um quadriciclo equipado com um aparelho de GPS. As amostras foram devidamente armazenadas e enviadas para análise química em laboratório especializado. Onde se determinou o pH em água (1:2,5 de solo:água); cálcio, extraído com solução de $\mathrm{KCl} 1 \mathrm{~mol} \mathrm{~L}{ }^{-1}$; P, extraído por Mehlich 1; a acidez potencial $(\mathrm{H}+\mathrm{Al})$ foi extraído com solução de acetato de cálcio utilizando-se metodologia proposta pela Embrapa (1997). Lançando mão da estatística descritiva, com auxílio do software Excel, elaboraram-se gráficos de distribuição de frequência, com base nas classes de teores (Tabela 1), segundo Cfsemg (1999).

Tabela 1. Níveis de fertilidade do solo para interpretação dos resultados.

\begin{tabular}{lcccccc}
\hline \multirow{2}{*}{ Atributo químico } & \multirow{2}{*}{ Unidade } & \multicolumn{4}{c}{ Classificação } \\
\cline { 3 - 7 } & & Muito baixo & Baixo & Médio & Alto & Muito alto \\
\hline pH (água) & & $<4,5$ & $4,51-5,40$ & $5,41-6,0$ & $6,1-7,0$ & $>7,0$ \\
Fósforo & $\mathrm{mg} \mathrm{dm}^{-3}$ & $\leq 4$ & $4,1-8,0$ & $8,1-12$ & $12,1-18$ & $>18,1$ \\
Cálcio & $\mathrm{cmol} \mathrm{d} \mathrm{dm}^{-3}$ & $\leq 0,4$ & $0,41-1,2$ & $1,21-2,40$ & $2,41-4,0$ & $>4,0$ \\
\hline
\end{tabular}

Fonte: adaptado de Cfsemg (1999) e Raij et al. 1996.

Observou-se que numa frequência acima de $40 \%$ das amostras analisadas (Figura 1), indicam solos com valores de
$\mathrm{pH}$ considerado baixo $(4,5-5,4)$ e muito baixo $(<4,5)$ o que pode ser indicativo de uma necessidade de correção da acidez dos 
solos, podendo ser também um reflexo de falhas no monitoramento da acidez destes solos, pela ausência de aplicação de calcário ao longo de várias safras agrícolas ou o uso aquém de doses de corretivos. Resultado semelhante foi obtido por Melo et al., (2003), avaliando a fertilidade dos solos do Estado de Roraima, onde verificaram que $52,9 \%$ dos solos apresentam acidez elevada à muito elevada.

$$
\mathrm{pH} \text { - Solos de Roraima }
$$



Figura 1. Distribuição de frequência para $\mathrm{pH}$ em $\mathrm{KCl}$ das amostras simples de solos, sob cultivos de soja e arroz nos municípios de Boa Vista e Bonfim, RR.

Com base na Figura 2, têm-se que 75,7 $\%$ das análises indicam teores de $\mathrm{Ca}^{+2}$ considerados baixo $\left(<1,5 \mathrm{cmol}_{\mathrm{c}} \mathrm{dm}^{-3}\right)$ e menos que $10 \%$ das mesmas, enquadramse numa classe de Alto à Muito Alto $(>4,0$ $\mathrm{cmol}_{\mathrm{c}} \mathrm{dm}^{-3}$ ), indicando características de solos extremamente pobres em cálcio, demostrando uma situação com implicações para o desenvolvimento das plantas cultivadas nestas áreas.

O efeito benéfico de Cálcio às diversas culturas foi reportado por Fageria et al., (1999). Os altos teores de $\mathrm{Ca}$ e $\mathrm{Mg}$ trocáveis no solo, aliados aos valores expressos de $\mathrm{pH}$ (Figura 1), reforçam a importância da prática da calagem, visando reduzir a toxidez de $\mathrm{Al}$ e aumentar a disponibilidade, principalmente, de macronutrientes no solo (PIRES et al., 2003).

Com relação à Figura 3, 75,5 \% das análises indicam teores de $\mathrm{P}$ considerados muito alto (RAIJ et al., 1996; CFSEMG, 1999), maior que $15 \mathrm{ppm}$, o qual pode ser explicado pelos efeitos residuais da aplicação de fertilizantes fosfatados em 
safras passadas, haja visto que os solos da Amazônia são pobres deste elemento, possuindo fósforo disponível de baixo a muito baixo. No entanto, respostas a doses médias de fósforo para a cultura do feijão foram obtidas por Silva et al. (1999) em LATOSSOLO AMARELO distrófico da savana roraimense, indicando que a capacidade de fixação de fósforo destes solos não é elevada, consequência da mineralogia do solo. Conforme Smyth (1996), 90\% dos solos de terra firme da Amazônia, não têm alta capacidade de fixação de fósforo, onde se considera a deficiência de $\mathrm{P}$, acidez e toxidez por $\mathrm{Al}^{3+}$ como as três principais restrições à fertilidade destes solos, o que contradiz os resultados obtidos neste trabalho.

\section{Ca disponível - Solos de Roraima}

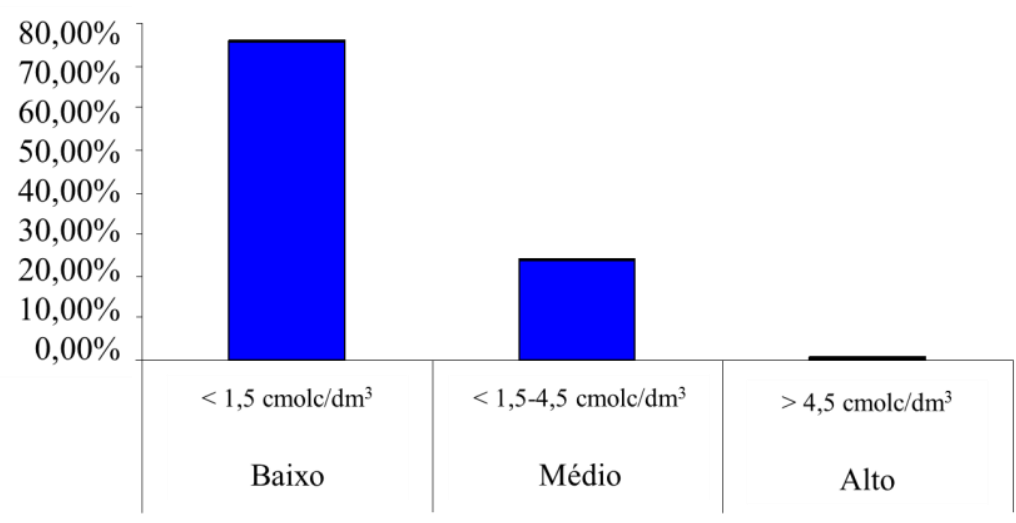

Figura 2. Distribuição de frequência para Cálcio Trocável $\left(\mathrm{Ca}^{+2}\right)$ das amostras simples de solos, sob cultivos de soja e arroz nos municípios de Boa Vista e Bonfim, RR.

\section{P disponível - Solos de Roraima}

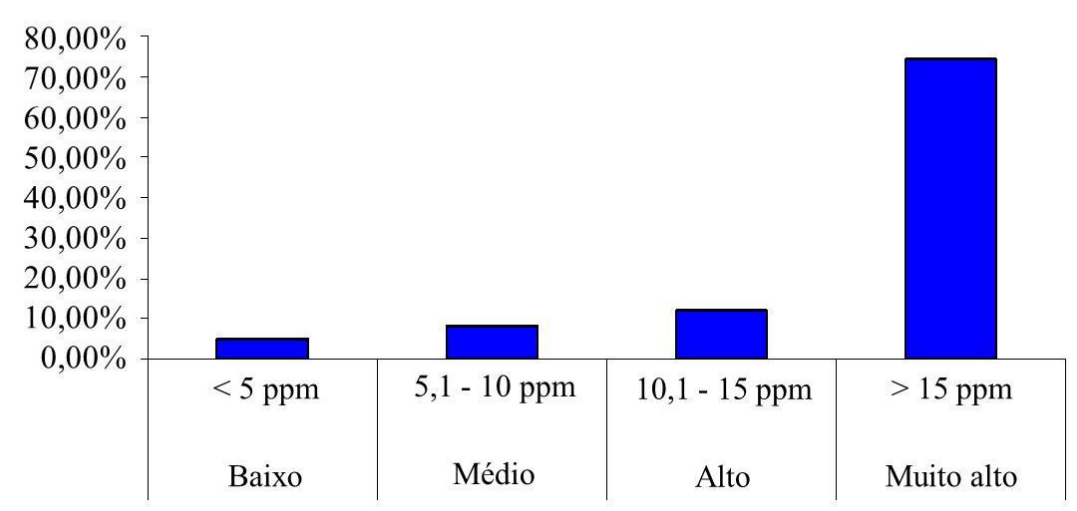

Figura 3. Distribuição de frequência para Fósforo disponível (P) das amostras simples de solos, sob cultivos de soja e arroz nos municípios de Boa Vista e Bonfim, RR. 
Para os solos avaliados com agricultura de precisão dos dois municípios, os atributos mostraram variação de níveis satisfatórios (P disponível) a deficientes (Ca disponível) e muito baixo $(\mathrm{pH})$.

\section{REFERÊNCIAS}

Companhia Nacional de Abastecimento. CONAB. Acompanhamento de safra brasileira: grãos, décimo levantamento, julho 2012 / Companhia Nacional de Abastecimento. - Brasília: Conab, 2012.

COSTA, M. C. G.; FERREIRA, G. B.; ARAÚJO, A, M. Apostila do curso de interpretação de análises de solos e recomendação de calagem e adubação no estado de Roraima. Boa Vista: Embrapa Roraima, 2008. 7 p. (Embrapa Roraima. Documentos, 08). Disponível em:<http://www.cpafrr.embrapa.br/embrap a/index.php/br/publicacoes/132-clima-esolos/298- >. Acesso em: 02 jun. 2013.

Empresa Brasileira de Pesquisa Agropecuária. EMBRAPA Manual de métodos de análise de solo. Rio de Janeiro: Centro Nacional de Pesquisa de Solos, 1997. 212p. Disponível em:< http://www.agencia.cnptia.embrapa.br/Rep ositorio/Manual+de+Metodos_000fzvhotq k02wx5ok0q43a0ram31wtr.pdf > Acesso em: 05 mar. 2013.
FAGERIA, N. K.; STONE, L. F.; SANTOS, A. B. dos. Maximização da eficiência de produção das culturas. Brasília: Embrapa Comunicação para Transferência de Tecnologia; Santo Antônio de Goiás: Embrapa Arroz e Feijão, 1999. 249 p.

MELO, V. F.; GIANLUPPI, D.; UCHÔA, S.C.P. Caracterização edafológica dos solos do Estado de Roraima. Boa Vista: Embrapa Roraima, 2003.p.12. (Embrapa Roraima. Boletim de Pesq. e Desen., 01). Disponível em: $<$ http://www.cpafrr.embrapa.br/embrapa/ind ex.php/br/publicacoes/132-clima-esolos/114-caracteristicas-edafologicas-dossolos-do-estado-de-roraima> Acesso em: 04 abr. 2013.

PIRES, F. R.; CATEN, A.; MARTINS, A. G.; ESPOSTI, M. D. D. Levantamento da fertilidade nas principais unidades de mapeamento do Espírito Santo. Revista Ciência Agronômica, v. 34, n. 2, p. 115123, 2003. Disponível em:< http://www.ccarevista.ufc.br/site/artigos_li sta.php?sel=2003\&sel2=2\&se13=34> Acesso em: 04 abr. 2013.

RAIJ, V. B.; CANTARELLA, H.; QUAGgIO, J. A.; FURLANI, A. M. C. Recomendações de adubação e calagem para o Estado de São Paulo. 2. Ed. Campinas: Instituto Agronômico de Campinas, Fundação IAC, 1996. 285 p. 
(Instituto Agronômico de Campinas.

Boletim Técnico, 100).

RIBEIRO, A. C.; GUIMARÃES, P. T. G.;

ALVAREZ, V. V. H. Comissão de

Fertilidade do Solo do Estado de Minas

Gerais - CFSEMG. Recomendações para

uso de corretivos e fertilizantes em

Minas Gerais: $5^{\text {a }}$ aproximação. Viçosa, MG: CFSEMG, 1999. 359 p. 